\title{
Risk Evaluation Method for Improvement of Railway Signalling Systems
}

\author{
Koji IWATA \\ Senior Researcher, \\ Train Control Systems Laboratory, \\ Ikuo WATANABE \\ Director \\ Signalling \& Telecommunications Technology Division
}

\begin{abstract}
High-level safety is essential for railway signalling systems, and so various measures are taken to prevent failures susceptible to lead to accidents based on the fail-safe concept, given that the type of accident cause by such a system failure is potentially serious. An International Standard, stipulating levels of reliability, availability, maintainability and safety for railway signalling systems, has recently been introduced. In this kind of system, safety is of utmost importance. However, considering the current requirement for highlevel of availability, this paper presents a case study on a risk evaluation, based on costs per unit of time, which can be used to represent not only safety factors but also availability.
\end{abstract}

Keywords: railway signalling systems, risk, safety and availability

\section{Introduction}

A high level of safety is essential in railway signalling systems. To this end, various measures based on the concept of fail-safe operation are taken to prevent failures, since such failures have the potential to cause a serious accident. In evaluating the safety of signalling systems, the Markov model, FTA (Fault Tree Analysis) and FMEA (Failure Modes and Effects Analysis) are applied. This paper proposes a method to evaluate the mitigation effectiveness of each safety measure and to improve systems efficiently by comparing these potential measures [1]

An International Standard, IEC 62278 [2], has recently been instituted focusing on the reliability $(R)$, availability (A), maintainability $(\mathrm{M})$ and safety (S) of railway signalling systems. In some cases, it became therefore necessary to analyse and evaluate such systems from the viewpoint of availability in addition to safety.

For this reason, the authors are studying a method to improve the availability of signalling systems while maintaining or improving on existing safety standards [3].

In the railway system, safety is the most important factor; today though attaining higher availability is also required at the same time. Given these circumstances, this study evaluates safety and availability of railway signalling systems based on the same measure: cost per hour as a result of failures related either to safety or availability.

This paper describes the result of this case study.

\section{Evaluation method for Risk calculation}

Availability (A) and safety (S) are each directly related to railway passengers, and these indices are influenced by reliability $(R)$ and maintainability $(M)$. Therefore, the RAMS for railway signalling systems can be divided into two areas: availability and safety. These indices are determined by the level of importance of the line based on its properties. One way of establishing this level is to examine the risk, defined by a combination of the failure occurrence frequency per hour and the resulting cost. Based on the risk factor for each line, the target values - such as the availability and safety of railway signalling systems on individual lines - can be determined.

To clarify, we define the risk as the cost per unit of time, which is equivalent to the cost caused by failure. The total amount of risk (including costs based on the loss related to life, loss in operating revenue and loss of equipments) is calculated by the following:

Risk $=\Sigma\left(\mathrm{a}_{\mathrm{i}} \times \mathrm{C}_{\mathrm{i}}\right)+\Sigma\left(\mathrm{s}_{\mathrm{j}} \times \mathrm{C}_{\mathrm{j}}\right)$

where:

$\mathrm{i}=$ Safe failure, which leads to accidents without any injury or fatality;

$\mathrm{j}=$ Dangerous failure, which leads to dangerous accidents;

$a_{i}=$ Occurrence frequency per unit time of a failure mode leading to safe failure;

$\mathrm{s}_{\mathrm{j}}=$ Occurrence frequency per unit time of a failure mode leading to dangerous failure;

$\mathrm{C}_{\mathrm{i}}=$ Costs related to $\mathrm{a}_{\mathrm{i}}$; and

$\mathrm{C}_{\mathrm{j}}=$ Costs related to $\mathrm{s}_{\mathrm{j}}$.

Note that each failure mode in railway signalling systems is determined using FTA and FMEA. 


\section{Case Study}

\subsection{System configuration}

\subsubsection{Definition of the "model line"}

Table 1 shows the preconditions in this evaluation model. The model line is divided into four sections A to D. Trains are operating a shuttle service between termini in both sections A and D. Figure 1 shows the layout in a station with interlocking devices. As the number of trains per hour is different between sections $\mathrm{C}$ and $\mathrm{D}$, the station, which is located closest to section $\mathrm{D}$ in section C, also has facilities for a shuttle service (Fig. 1 Type (c)).

On the "model line" frequency of failure occurrence and the downtime values are the same for each section, and so operational time is assumed to be 19 hours.

\section{1.2 Equipment to be evaluated}

The systems to be evaluated comprise the train operation control system, interlocking devices, point machines, signals and track circuits. Figure 2 shows the number of pieces of equipment in each section.

\subsection{Identification of the causes leading to railway signalling equipment failures}

Fault modes in the target equipment are identified using FTA. We applied FTA, in order to identify the events leading to what are described as life threatening failures (dangerous failures) and failures threatening availability alone (safe failures). In the FTA for dangerous failures, collisions and derailments are located at top of the list of events, and in the case of safe failures stop aspects and signal blackouts appear.

Since events will differ, depending on whether the section is in the area between two stations or actually in a station with interlocking devices, a separate FTA is applied for each case (Fig. 3).

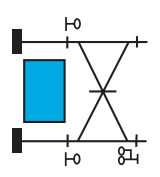

Type (a)

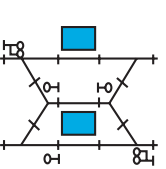

Type (d)

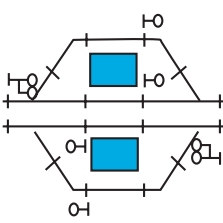

Type (b)

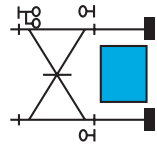

Type (e)

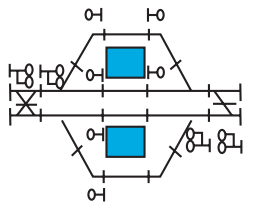

Type (c)
Fig. 1 Layout in a station with interlocking devices

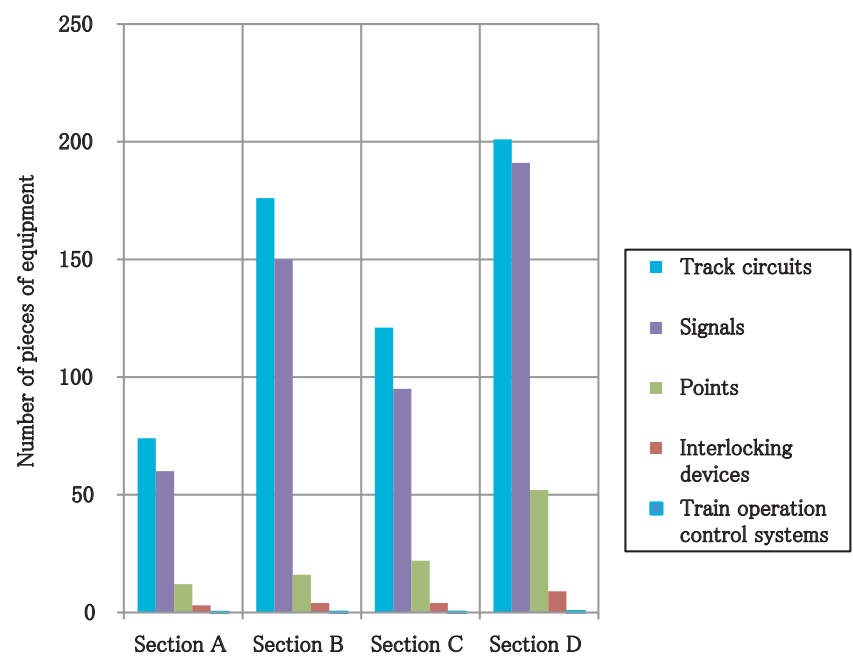

Fig. 2 The number of pieces of equipment on a model line

\subsection{Identifying the sequence of events leading to accidents caused by railway signalling systems}

Railway signalling systems are designed the probability of a dangerous failure to a minimum. If such a failure was to occur in a railway signalling system, its frequency

Table 1 Preconditions for the evaluation model

\begin{tabular}{|c|c|c|c|c|c|}
\hline & Section A & Section B & Section C & Section D \\
\hline \multicolumn{2}{|c|}{ Length of section $[\mathrm{km}]$} & 10 & 28 & 15 & 81 \\
\hline \multirow{5}{*}{$\begin{array}{l}\text { Number of } \\
\text { stations } \\
\text { with } \\
\text { interlocking } \\
\text { devices }\end{array}$} & Type (a) & 1 & 0 & 0 & 0 \\
\hline & Type (b) & 2 & 4 & 3 & 0 \\
\hline & Type (c) & 0 & 0 & 1 & 0 \\
\hline & Type (d) & 0 & 0 & 0 & 8 \\
\hline & Type (e) & 0 & 0 & 0 & 1 \\
\hline \multicolumn{2}{|c|}{ Interval between signals [km] } & 0.44 & 0.44 & 0.44 & 1.3 \\
\hline \multicolumn{2}{|c|}{ Number of train services [trains / h] } & 22 & 22 & 22 & 5 \\
\hline \multicolumn{2}{|c|}{ Number of trainsets } & 80 & 80 & 80 & 20 \\
\hline \multicolumn{2}{|c|}{$\begin{array}{l}\text { Congestion rates [\%] } \\
\text { * Official capacity } \\
100 \text { passengers/car }\end{array}$} & 150 & 150 & 150 & 100 \\
\hline
\end{tabular}




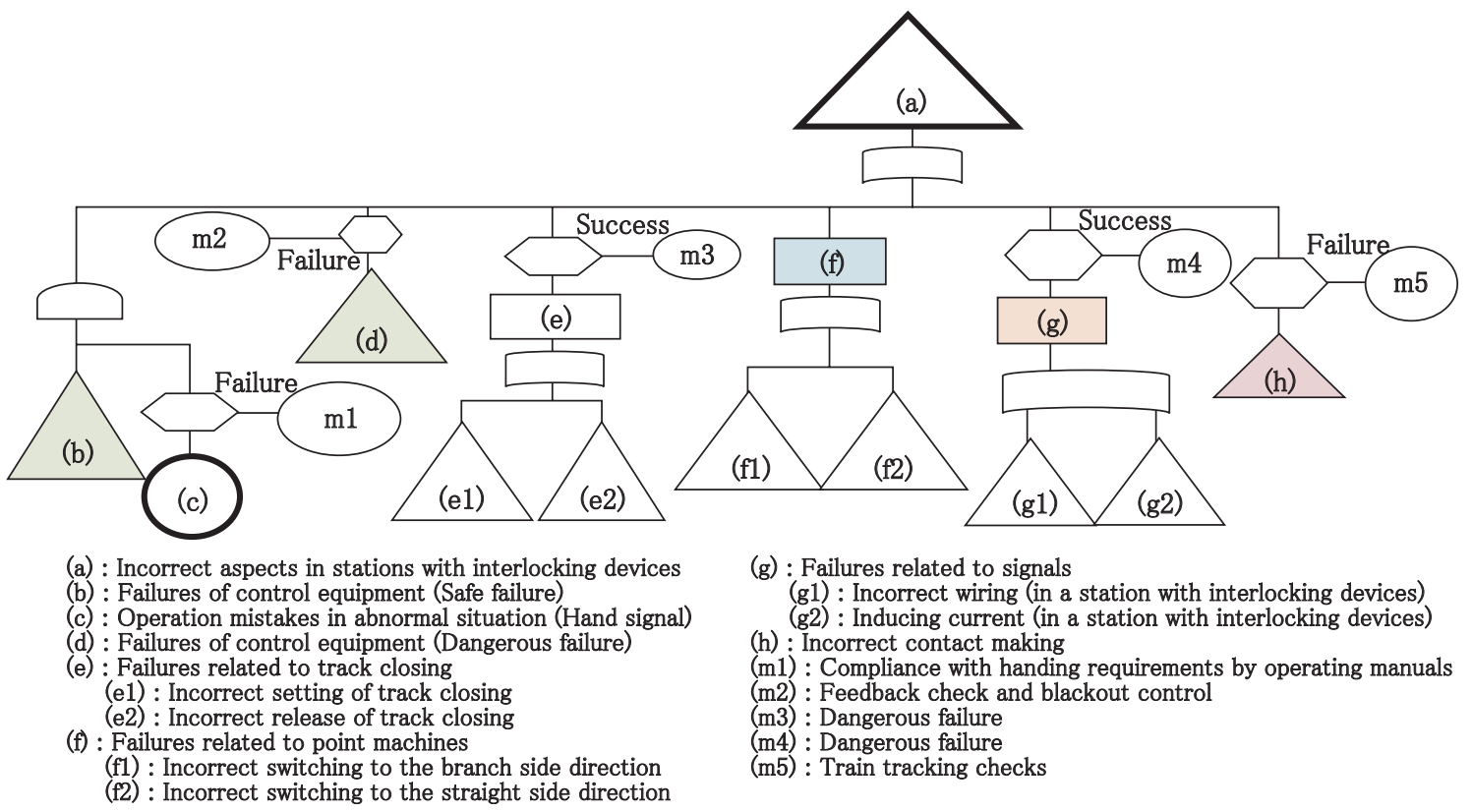

Fig. 3 An example of FTA for incorrect aspects in a station with interlocking devices (Extract)

and level of consequences resulting from the accident such as a collision or a derailment will be reduced by extraneous factors such as absence of a preceding train. In order to evaluate the mitigation effect of these factors on the accident, ETA (Event Tree Analysis) is applied.

\section{3. 1 Identification of events to be analysed}

ETA is applied to failures identified by FTA as shown in Table 2. A part of the results of ETA on incorrect aspects in stations with interlocking devices is shown in Fig.4. Note that, "Incorrect aspects in stations with interlocking devices" is the top event in the FTA shown in Fig.3.
In this report, the six factors related to railway signalling systems shown in Table 2 are named accidents factors.

\section{3. 2 Calculation of frequency of occurrence}

The failure frequency is assigned using information in the railway safety database managed by the Railway Technology Promotion Center at the RTRI (Table 3). Concretely, this information is based on failure data for the specific section (about $50 \mathrm{~km}$, with 15 interlocking devices) of about five years. For those failures which have not yet occurred in the latter specific section, the target section to be analysed is expanded (about $17,000 \mathrm{~km}$, with approxi-

Table 2 Accidents factors

\begin{tabular}{|c|c|c|c|c|}
\hline \multirow[t]{2}{*}{ Classification } & \multirow[t]{2}{*}{ ID } & \multirow[t]{2}{*}{ Accident factors } & \multicolumn{2}{|c|}{$\begin{array}{c}\text { Possibility of occurrence } \\
\text { (Yes / No) }\end{array}$} \\
\hline & & & $\begin{array}{l}\text { In a section be- } \\
\text { tween stations } \\
\text { with interlock- } \\
\text { ing devices }\end{array}$ & $\begin{array}{l}\text { In a station } \\
\text { with inter- } \\
\text { locking de- } \\
\text { vices }\end{array}$ \\
\hline \multirow[t]{4}{*}{ Dangerous failures } & (1) & Incorrect aspect & Yes & Yes \\
\hline & (2) & $\begin{array}{l}\text { Incorrect switching un- } \\
\text { der passing train }\end{array}$ & No & Yes \\
\hline & (3) & $\begin{array}{l}\text { Loss of contact with } \\
\text { switches }\end{array}$ & No & Yes \\
\hline & (4) & $\begin{array}{l}\text { Undetectable obstacle } \\
\text { between rails related to } \\
\text { points }\end{array}$ & No & Yes \\
\hline \multirow[t]{2}{*}{ Safe failures } & (5) & Blackout & Yes & Yes \\
\hline & (6) & Unintended stop aspect & Yes & Yes \\
\hline
\end{tabular}


Table 3 Frequency of failures

\begin{tabular}{|c|c|c|c|c|}
\hline & Failure & $\begin{array}{l}\text { Frequency } \\
{[/ \mathrm{h}]}\end{array}$ & $\begin{array}{c}\text { Average } \\
\text { downtime } \\
{[\mathrm{h}]}\end{array}$ \\
\hline \multirow{8}{*}{ (1) } & A & Operational mistake at time of control equipment safe failure & $3.19 \times 10^{-8}$ & 0.24 \\
\hline & A & Control of safety impossible after control equipment failure (Dangerous failure) & $1.00 \times 10^{-10}$ & 2.00 \\
\hline & $\mathrm{A}$ & Failure related to point machines (Dangerous failure) & $9.09 \times 10^{-10}$ & 3.48 \\
\hline & A & Failure related to track closing (Dangerous failure) & $1.35 \times 10^{-8}$ & 0.03 \\
\hline & A & Failure related to signals (Dangerous failure) & $1.00 \times 10^{-10}$ & 2.00 \\
\hline & A & Undetected train tracking error after track circuit failure (Loss of contact) & $4.27 \times 10^{-10}$ & 0.92 \\
\hline & $\mathrm{B}$ & Failure related to signals (Dangerous failure) & $1.00 \times 10^{-10}$ & 2.00 \\
\hline & $\mathrm{B}$ & Failure related to track circuits (Incorrect contact making) & $1.00 \times 10^{-10}$ & 2.00 \\
\hline (2) & $\mathrm{A}$ & Incorrect switchings under passing train & $4.55 \times 10^{-10}$ & 9.42 \\
\hline (3) & $\mathrm{A}$ & Loss of contact with switches & $1.00 \times 10^{-10}$ & 2.00 \\
\hline (4) & A & Undetectable obstacles between rails related to points (Dangerous failure) & $1.20 \times 10^{-10}$ & 2.00 \\
\hline \multirow{5}{*}{ (5) } & A & Successful control of safety after control equipment failure & $1.00 \times 10^{-10}$ & 2.00 \\
\hline & A & Failure related to power supply (Blackout) & $1.90 \times 10^{-7}$ & 1.40 \\
\hline & $\mathrm{A}$ & Failure related to signals (Blackout) & $5.36 \times 10^{-9}$ & 0.86 \\
\hline & $\mathrm{B}$ & Failure related to signals (Blackout) & $1.84 \times 10^{-7}$ & 1.94 \\
\hline & $\mathrm{B}$ & Failure related to power supply (Blackout) & $2.76 \times 10^{-7}$ & 0.97 \\
\hline \multirow{14}{*}{ (6) } & $\mathrm{A}$ & Incorrect drop down (Failure of track circuits related routes) & $3.16 \times 10^{-7}$ & 1.39 \\
\hline & $\mathrm{A}$ & Brownout or blackout of power supply for interlocking devices & $3.81 \times 10^{-7}$ & 0.83 \\
\hline & A & Failure of control equipment related to point machines (Safe failure) & $1.47 \times 10^{-6}$ & 3.28 \\
\hline & A & Failure of control equipment related to signals (Safe failure) & $1.47 \times 10^{-6}$ & 3.28 \\
\hline & A & Failure of point machines (Switching impossible) & $5.88 \times 10^{-7}$ & 0.60 \\
\hline & A & Operational mistake or train operation control system failure & $5.71 \times 10^{-7}$ & 0.30 \\
\hline & A & Failure of system terminal or operation mistake & $3.81 \times 10^{-8}$ & 0.00 \\
\hline & $\mathrm{A}$ & Failure of route control systems or incottect control & $1.47 \times 10^{-6}$ & 0.57 \\
\hline & A & Failure of network nodes of a train operation control system & $9.68 \times 10^{-7}$ & 0.78 \\
\hline & A & Failure of networks between route control systems and interlocking devices or incorrect control & $1.00 \times 10^{-10}$ & 2.00 \\
\hline & A & Failure related to track closing (Safe failure) & $1.47 \times 10^{-6}$ & 0.68 \\
\hline & A & Failure related to signals (Stop aspect) & $1.04 \times 10^{-7}$ & 0.78 \\
\hline & $\mathrm{B}$ & Incorrect drop down (Failure of track circuit related to blocks) & $1.98 \times 10^{-7}$ & 0.29 \\
\hline & $\mathrm{B}$ & Failure related to signals (Stop aspect) & $2.69 \times 10^{-9}$ & 0.46 \\
\hline & $\begin{array}{l}\text { A } \\
\text { B }\end{array}$ & \multicolumn{3}{|l|}{$\begin{array}{l}\text { In a station with interlocking devices } \\
\text { In a section with no interlocking devices between stations }\end{array}$} \\
\hline
\end{tabular}

mately 2,800 interlocking devices), and the value of the dangerous failure frequency is assigned according to the failure data for five years, and the value for safe failure frequency is assigned based on the failure data for one year. If there is no interlocking failure (of the approximately 2,800 devices) in five years over the expanded section, the occurrence frequency per unit time is calculated to be less than about $10^{-8}$.

Note that, the number of pieces of equipment in the expanded section is converted by a distance ratio (327 times larger than the specific section), or the number ratio for stations with interlocking devices (185 times larger than the specific section). Moreover, the frequency of a failure which has not occurred in this expanded area is assumed to be $10^{-10} / \mathrm{h}$.

\section{3. 3 Identifying the sequence of events leading to an accident}

When an accident factor occurs, it does not necessarily lead directly to an accident. Each factor which may reduce the occurrence frequency of a collision or derailment is set to a branch condition in ETA. These branch conditions are categorised into (1) reduction factors based on obstacle occurrence probabilities, (2) reduction factors based on measures and (3) reduction factors based on self avoidance of an obstacle (Fig.4).

(1) Reduction factors based on obstacle occurrence prob- abilities

It is assumed that the occurrence probability for each obstacle is composed of both (a) probabilities of an obstacle occupying a section and (b) occurrence probabilities of an obstacle itself. Hereafter the outline of the assumed values in each section is described.

(a) Probabilities of an obstacle occupying a section

An obstacle in the way of a train is assumed to be one of the following: a preceding train, an oncoming train, maintenance work. Assumed probabilities for the presence of an obstacle in a section are shown in Table 4. It is assumed that obstacles do not appear simultaneously. The occupancy probability value is assumed to be same for all sections.

(b) Probability of an obstacle occurring

\section{Probability of a preceding train:}

Between sections $\mathrm{A}$ and $\mathrm{C}$, the probability of a preceding train occupying a section is assumed to be 0.8 . Note that, in the case of an error stop aspect (Table 2 ID 6), this value is assumed to be 0.1 .

As for section $\mathrm{D}$, this value is assumed to be 0.2 , given that there are only one quarter of the total number of trains.

\section{Probability of an oncoming train:}

This value is calculated by: number of shuttle service final stop stations / number of stations with interlocking devices.

Probability of maintenance work: 


$\begin{array}{lll}\begin{array}{ll}\text { (1) Reduction factors based } \\ \text { on obstacle occurrence }\end{array} & \begin{array}{l}\text { (2) Reduction factors } \\ \text { based on measures }\end{array} & \begin{array}{l}\text { (3) Reduction factors } \\ \text { based on self avoidance } \\ \text { probabilities }\end{array} \\ \end{array}$

\begin{tabular}{|l|l|l|l|l|}
\hline $\begin{array}{l}\text { PROBABILITY } \\
\text { OF OBSTACLE } \\
\text { OCCUPYING A } \\
\text { SECTION }\end{array}$ & $\begin{array}{l}\text { PROBABILITY } \\
\text { OF OBSTACLE } \\
\text { OCCUPYING }\end{array}$ & WVOIDED & $\begin{array}{l}\text { AVOIDED BY } \\
\text { CREW }\end{array}$ & SELF AVOIDED \\
\hline
\end{tabular}

Consequence

levels of accidents

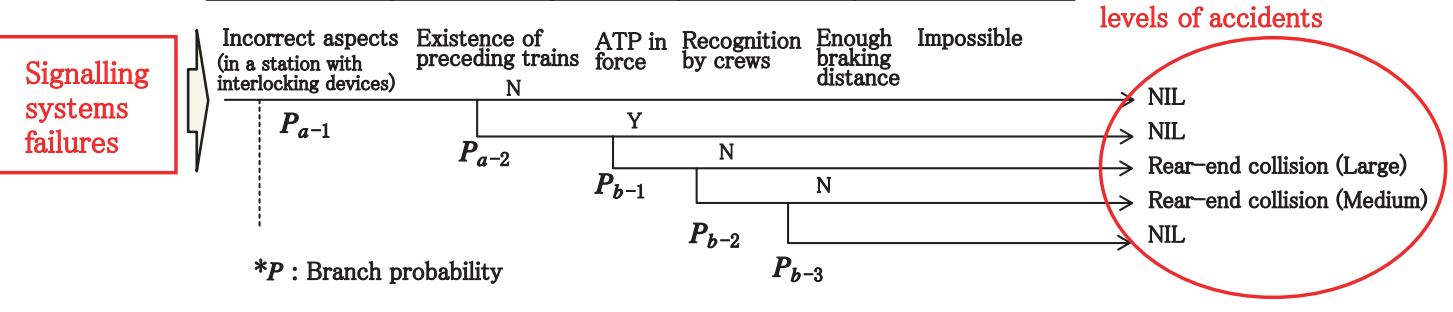

Fig. 4 An example of ETA for incorrect aspects (Extract)

Table 4 Type of obstacle and probability of presence (Estimated value)

\begin{tabular}{|c|c|c|}
\hline Type of obstacle & $\begin{array}{c}\text { In a section with } \\
\text { no interlocking } \\
\text { devices, between } \\
\text { stations }\end{array}$ & In a station with interlocking devices \\
\hline Preceding train & 0.98 & 0.49 \\
\hline Oncoming train & 0.00 & 0.49 \\
\hline Maintenance work & 0.02 & 0.02 \\
\hline \hline Total & 1 & 1 \\
\hline
\end{tabular}

Between sections $\mathrm{A}$ and $\mathrm{C}$, the probability of meeting maintenance work is assumed to be 0.1 . As for section $\mathrm{D}$, this value is assumed to be 0.025 , given that there are only a quarter of the total number of trains.

The probability of the presence of a train on a turnout, is assumed to be 0.093 for sections A, B and C, and 0.015 for section $\mathrm{D}$.

(2) Reduction factors based on measures

Measures describe actions to be executed by the ATP (Automatic Train Protection) and the crew. This means for example factoring into the branch conditions whether or not the braking distance, at the time when an obstacle is noticed by the crew, is enough to avoid an accident. As for the ATP, this value is assumed to be $10^{-6}$ based on the device's failure occurrence probability. In terms of crew, given the difficulty in determining an exact value, it is assumed to be 0.5 .

(3) Reduction factors based on self avoidance of the obstacle (Fig.4)

This factor assumes that the obstacle is avoided either by the oncoming train or maintenance worker themselves or because of facing points. These branch probabilities are difficult to determine and so they are assumed to be 0.5 .

Note that, given an operational window of 19 hours, the probabilities of these values assigned in the ETA are multiplied by 0.79 (19 hours/ 24 hours). ATP which works according to signal aspects.

\section{3. 4 Analysis to identify factors which can mitigate dangerous accidents after a failure}

The degree to which the frequency of a dangerous accident caused by a failure can be mitigated is calculated by dividing the frequency of the dangerous accident by the frequency of each accident factor shown in Table 2. The results are shown in Fig.5.

The frequency of the dangerous accidents related to (5) blackouts and (6) unintended stop aspects results in small values, because it is expected that the ATP will function effectively. On the other hand, in the case of incorrect signalling aspects, the degree to which the dangerous accident frequency can be mitigated is lower since it is no longer possible to rely on the performance of the

Note that, the mitigation degree in section $\mathrm{D}$ is higher than in other sections, because the number of train services in section $\mathrm{D}$ is lower. The mitigation degree for turnout related failures such as (2), (3), (4) shown in Fig. 5, is influenced by the length of time spent by a train on a turnout.

Although the branch probabilities in the ETA include many estimations, comparison of the mitigation effect of each factor defined as a branch condition in ETA is effective. 


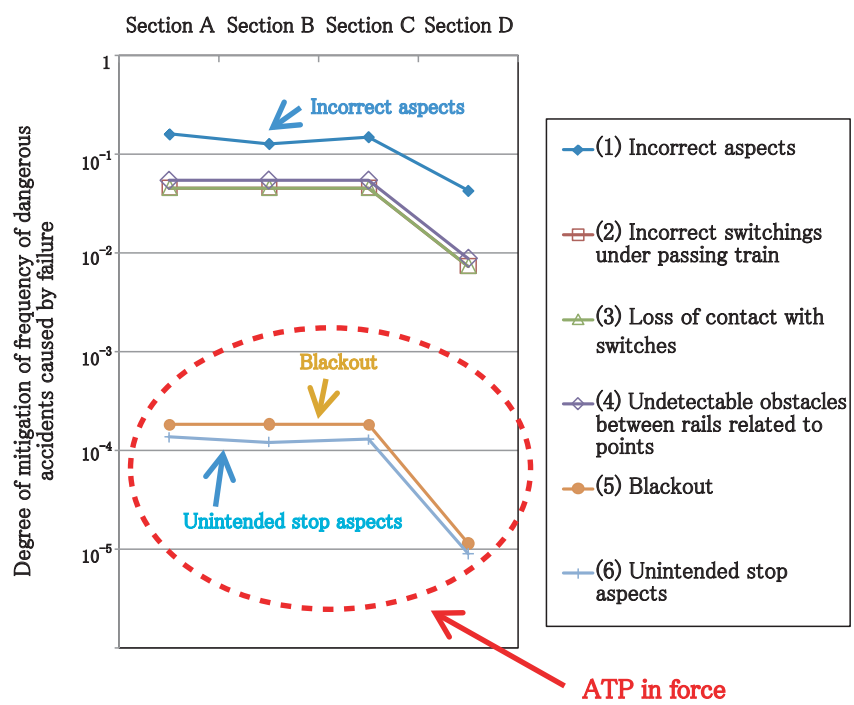

Fig. 5 Degree of mitigation of frequency of dangerous accidents caused by failure (Based on estimated values)

\subsection{Calculation of cost}

\section{4.1 Definition of cost}

Cost is categorised into cost related to loss of life, cost of loss of equipment, and cost of loss in operating revenue.

(1) Cost related to loss of life $(\mathrm{Cl})$

$\mathrm{Cl}=(\mathrm{Cf} \times \mathrm{Nf}+\mathrm{Ci} \times \mathrm{Ni})$

Cf : Fatality cost

$\mathrm{Nf}$ : Number of fatalities

$\mathrm{Ci}$ : Injury cost

$\mathrm{Ni}$ : Number of injuries

Values assigned to employees (operating staff) and the general public are different.
(2) Cost of loss of equipment $(\mathrm{Ce})$

$\mathrm{Ce}=(\mathrm{Cvf} \times \mathrm{Nvf}+\mathrm{Cvp} \times \mathrm{Nvp})+\mathrm{Crs}+\mathrm{Cre}+(\mathrm{Cp} \times$ $\mathrm{Np})$

Cvf : Cost of car destroyed

Cvp : Cost of partially damaged car

Nvf : Number of destroyed cars

Nvp : Number of partially damaged cars

Crs : Cost of repairs on signalling equipment

Cre : Cost of repairs on equipment other than signalling equipment

$\mathrm{Cp}$ : Cost of loss due to passenger insured belongings

$\mathrm{Np}:$ Number of persons in damaged cars

(3) Cost of loss in operating revenue ( $\mathrm{Co})$

$\mathrm{Co}=\mathrm{Cs} \times \mathrm{Ts}$

Cs : Cost of loss from suspension of train service in an hour

Ts : Downtime

Each value is assigned, based on the level of consequence of an accident which is defined in ETA sequences.

\section{4 .2 Definition of the level of consequence of an accident}

Levels of consequence of an accident are categorised into four levels: High, Medium, Low and Nil. Each sequence in ETA is assigned a level (Fig. 4). The total scale of the cost is calculated using the definition for magnitude of cost (Table 5) and definition of impact of cost in an accident (Table 6 ). When the level of consequence level is place in the Nil category, the total scale of the cost will be calculated only on the basis of loss in terms of operating revenue. In this evaluation, time to recovery is assumed to be the same as the maximum delay time. The time to recovery of equipment is estimated to be the same as the average time, which is calculated as the total maximum delay time of due to equipment failure in relation to the

Table 5 Scale of cost (Estimated value)

\begin{tabular}{|l|l|}
\hline \multicolumn{1}{|c|}{ Item } & \multicolumn{1}{c|}{ Size of cost } \\
\hline General public & $\begin{array}{l}15,000 / \text { a fatality } \\
200 / \text { an injury }\end{array}$ \\
\hline Employee & $\begin{array}{l}10,000 / \text { a fatality } \\
200 / \text { an injury }\end{array}$ \\
\hline Destroyed car & $10,000 /$ Car \\
\hline Damaged car & $5,000 /$ Car \\
\hline Repair (Except for signalling & $\begin{array}{l}\text { Section A,C,D (2,000) } \\
\text { Section B (4,000) } * \text { Elevated railway section } \\
\text { Note that accidents related to an oncoming train }(6,000)\end{array}$ \\
\hline $\begin{array}{l}\text { Repairs to signalling equip- } \\
\text { ment }\end{array}$ & 1,000 \\
\hline Insurance on belongings & $\begin{array}{l}\text { Loss incurred by suspension } \\
\text { of train service in an hour }\end{array}$ \\
\hline $\begin{array}{l}\text { Section A (1,200) } \\
\text { Section B (1,200) } \\
\text { Section D (100) }\end{array}$ \\
\hline
\end{tabular}


Table 6 Definition of cost in an accident on the model line (Estimated value)

\begin{tabular}{|c|c|c|c|c|c|c|c|c|c|}
\hline $\begin{array}{l}\text { Type of } \\
\text { obstacle }\end{array}$ & $\begin{array}{l}\text { Conse- } \\
\text { quence } \\
\text { level of } \\
\text { accident }\end{array}$ & $\begin{array}{l}\text { Number } \\
\text { of de- } \\
\text { stroyed } \\
\text { cars }\end{array}$ & $\begin{array}{l}\text { Number } \\
\text { of dam- } \\
\text { aged cars }\end{array}$ & $\begin{array}{l}\text { Number of } \\
\text { employee } \\
\text { fatalities }\end{array}$ & $\begin{array}{l}\text { Number } \\
\text { of injured } \\
\text { employ- } \\
\text { ees }\end{array}$ & $\begin{array}{l}\text { Number of } \\
\text { damaged } \\
\text { cars }\end{array}$ & $\begin{array}{l}\text { Passen- } \\
\text { ger fatal- } \\
\text { ity rate }\end{array}$ & $\begin{array}{l}\text { Passenger rate } \\
\text { of injury }\end{array}$ & Downtime [h] \\
\hline \multirow{4}{*}{$\begin{array}{l}\text { Preced- } \\
\text { ing train } \\
\text { or On- } \\
\text { coming } \\
\text { train }\end{array}$} & High & 2 & 1 & 2 & 0 & 2.5 & 0.2 & 0.8 & 1,200 \\
\hline & Medium & 1 & 1 & 1 & 1 & 1.5 & 0.02 & 0.98 & 40 \\
\hline & Low & 0 & 1 & 0 & 2 & 0.5 & 0 & 1 & 5 \\
\hline & Nil & 0 & 0 & 0 & 0 & 0 & 0 & 0 & $\begin{array}{l}\text { Depends on } \\
\text { equipment } \\
\text { (Table 3) }\end{array}$ \\
\hline \multirow{4}{*}{$\begin{array}{l}\text { Mainte- } \\
\text { nance } \\
\text { work }\end{array}$} & High & 2 & 1 & 10 & 0 & 2.5 & 0.05 & 0.95 & 24 \\
\hline & Medium & 1 & 1 & 5 & 5 & 1.5 & 0.01 & 0.99 & 12 \\
\hline & Low & 0 & 1 & 0 & 10 & 0.5 & 0 & 1 & 3 \\
\hline & Nil & 0 & 0 & 0 & 0 & 0 & 0 & 0 & $\begin{array}{l}\text { Depends on } \\
\text { equipment } \\
\text { (Table 3) }\end{array}$ \\
\hline
\end{tabular}

frequency for a period of about five years (Table 3).

Note that, in the case of an accident, it is assumed that train services are suspended in both directions.

\section{4 .3 Identification of areas for improvement based on cost}

Areas to be improved are identified through maximum risk, or where total scale of cost is highest in one year. Cost associated to each piece of equipment is calculated as follows: First, the costs incurred by each event defined in FTA are calculated for a one year period; secondly, costs associated to each of these events are broken down to equipment type and then finally a sum of total costs associated to each type of equipment is calculated from the costs calculated for each event.
The highest costs in one year are generated by "interlocking devices", as shown in Fig. 6(a). Whereas "operational mistakes" committed when there is a failure in control equipment turned out to be the main cause of events. Note that, operational mistakes account for approximately half of total cost, as shown in Fig. 6(b).

\section{Risk evaluation calculation results}

Figure 7 shows risk factors for each piece of railway signalling equipment in the model in terms of both danger index for system safety, and downtime for availability. The danger index means the number of fatalities in one year, caused by failures in the railway signalling system and is calculated on the basis of assumptions listed

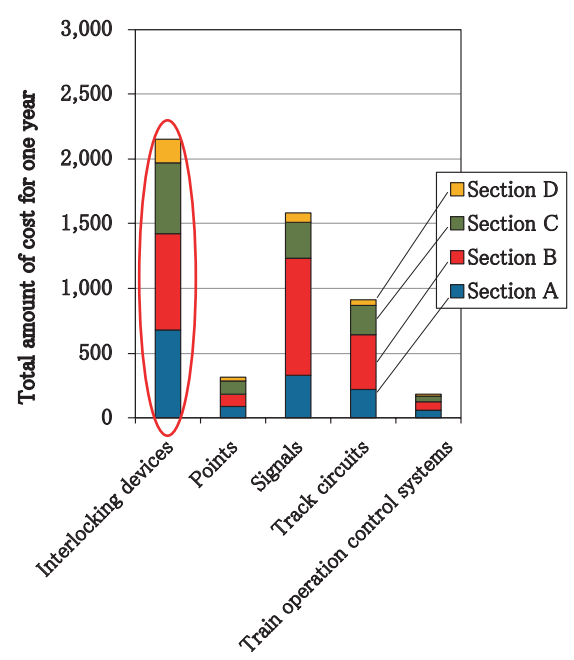

(a) Cost of each equipment

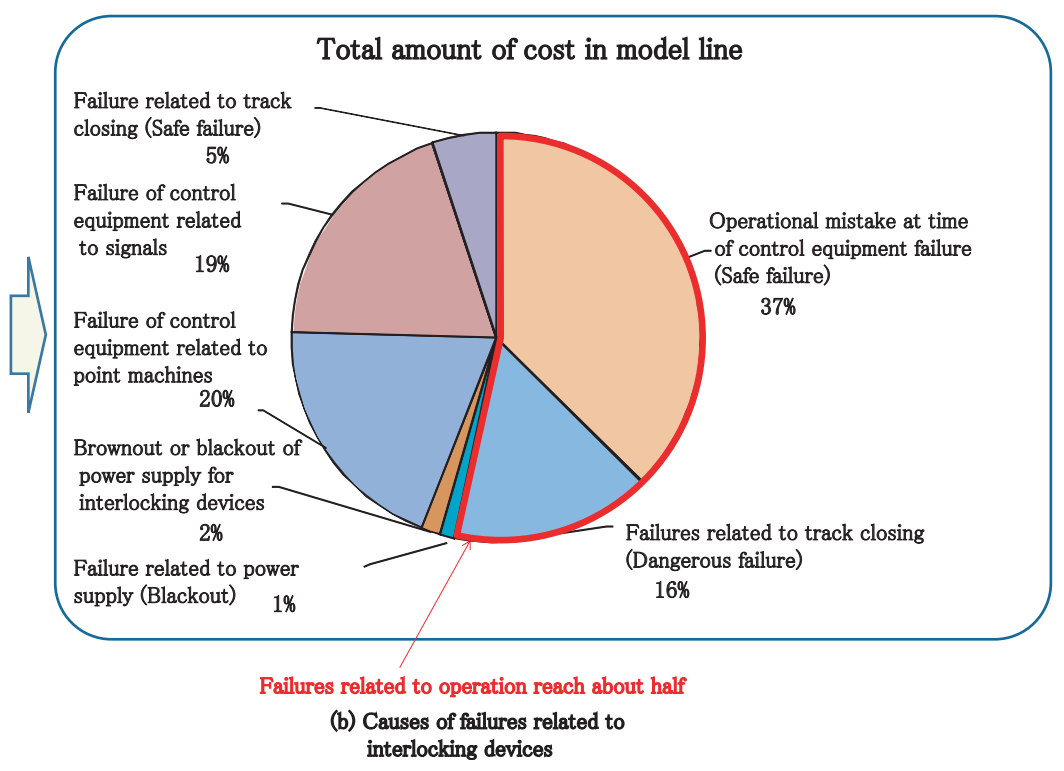

interlocking devices
inses of failures relate

Fig. 6 Cost per type of equipment in one year for the model line with breakdown (Based on estimated values) 


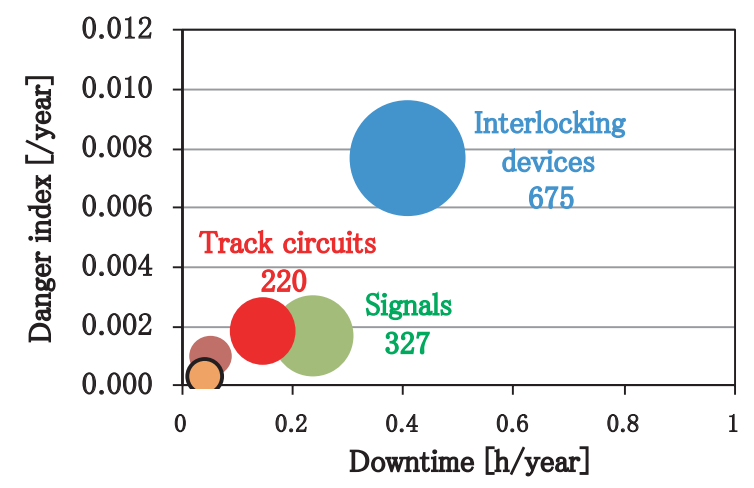

(a) Section A

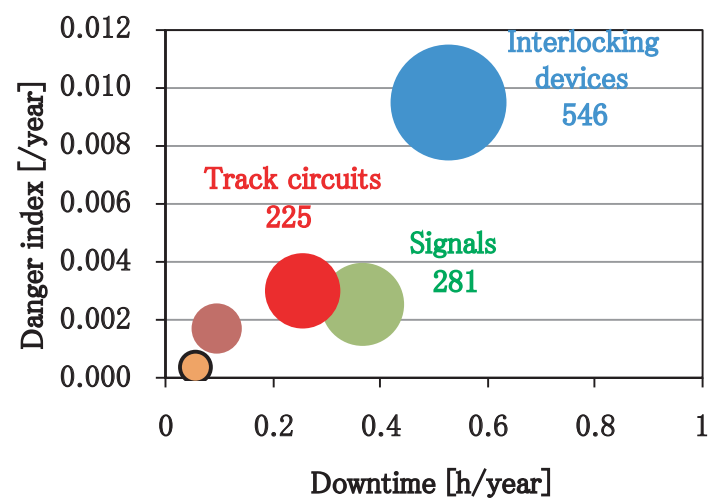

(c) Section C

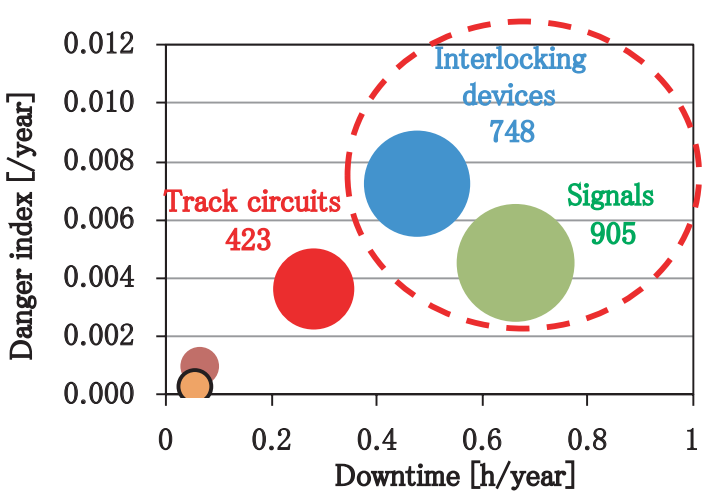

(b) Section B

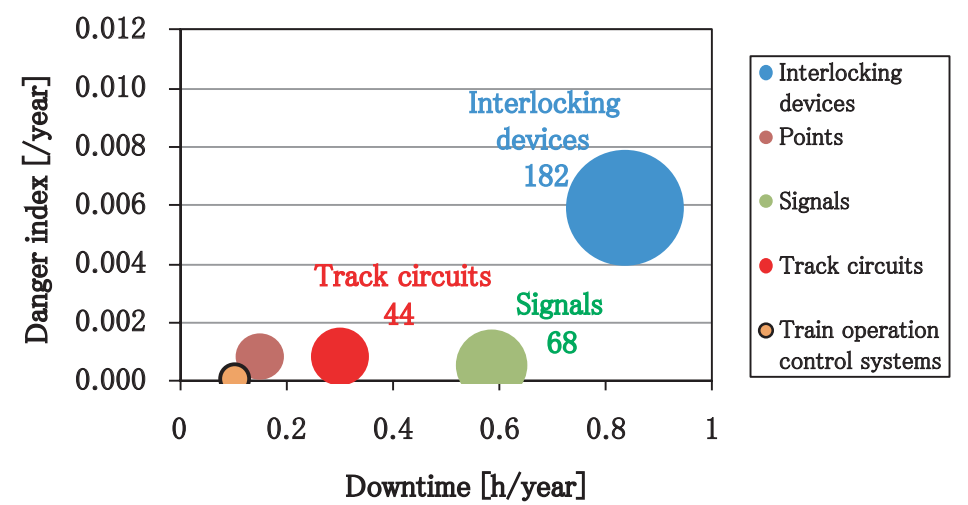

(d) Section D

Fig. 7 Relationship between danger index, downtime, and risk per railway signalling system on the model line (Based on estimated values)

* The area of each circle represents the scale of cost related to each type of equipment in a year (Risk).

in Table 6. Risk is calculated by multiplying the frequency of failure by the total cost incurred by the failure.

The type of equipment to be improved in terms not only of the danger index but also downtime is interlocking devices, for sections $\mathrm{A}, \mathrm{C}$ and $\mathrm{D}$. However in section $\mathrm{B}$, the equipment with the highest danger index differs from the one with the longest downtime. Concretely, according to the results interlocking devices have the highest danger index. But in terms of longest downtime, signals come out top. Therefore, based on this analysis, the priority for improvement is signalling equipment, since the total area of the circle on the graph representing overall risk is larger for signalling equipment than for interlocking devices.

These results suggest that based on the assumption that the danger index for railway signalling systems is kept at a sufficiently low level, this evaluation method, which can identify the type of equipment to be improved based on a risk which is calculated by multiplying the frequency of failure and the cost incurred by each failure, can be a helpful tool in ensuring proactive and well balanced investment.

\section{Conclusion}

In any railway system, safety is of utmost importance but at the same time nowadays, availability is also considered to be of primary importance. As such this paper proposes a method for evaluating safety and availability of railway signalling systems based on risk, which was applied to a model line.

The results demonstrate that it is possible to identify which equipment can be improved based on risk which is calculated using total costs for one year, although some values are estimated.

Risk evaluation focusing on railway signalling systems as a whole can clarify the influence of a failure in a system, help identify what needs to be improved and can serve as an effective investment tool. Even though some values remain as estimates, results can be helpful in the review of a qualitative analysis.

We think that, for a more detailed analysis it is necessary to assign more reliable data to the assumed data. To this end, failure data needs to be managed according to the number of types of equipment, equipment failure modes and the types of equipment on each line. Management of such data should be easy if a suitable support tool is introduced.

This proposed evaluation method and subsequent refinement of data which for the moment is assumed, will make railway signalling systems more dependable and give reassurance to passengers. 


\section{References}

[1] K. Iwata, I. Watanabe, Y. Hirao, S. Hiraguri, H. Nakamura, "Study on quantitative Evaluation Methods for Safety of Railway Signalling Systems," Proceedings of International Symposium on Speed-up and Service Technology for Railway and Maglev Systems, Tokyo, 2003.
[2] IEC 62278. Railway applications -Specification and demonstration of reliability, availability, maintainability and safety (RAMS), 2002.

[3] K. Iwata, S. Hiraguri, I. Watanabe, "Evaluation Methods for Railway Signalling Systems from the Viewpoint of Availability," Quarterly Report of QR of RTRI, Vol.50, No.3, Aug. 2009. 